\title{
Digital ophthalmology in Scotland: benefits to patient care and education
}

This article was published in the following Dove Medical Press journal: Clinical Ophthalmology

\author{
Roxanne Annoh' \\ Sirjhun Patel ${ }^{2}$ \\ Daniel Beck' \\ Heather Ellis ${ }^{3,4}$ \\ Bal Dhillon ${ }^{1,4}$ \\ Roshini Sanders ${ }^{4,5}$
}

'Princess Alexandra Eye Pavilion, Edinburgh, UK; ${ }^{2}$ Ophthalmology Department, Ninewells Hospital, Dundee, UK; ${ }^{3}$ Ophthalmology Department, Lauriston Building, Edinburgh, UK; ${ }^{4}$ University of Edinburgh, Edinburgh, UK; ${ }^{5}$ Queen Margaret Hospital, Dunfermline, UK
Correspondence: Roxanne Annoh Princess Alexandra Eye Pavilion, 45 Chalmers Street, Edinburgh EH3 9HA, UK

Tel +44 I3I 536 I628

Email roxanne.annoh@nhs.net

\begin{abstract}
Tackling visual impairment remains an important public health issue. Due to limited resources and the increasing demand on hospital eye services (HES), delivery of quality eye care within the community is essential. Training of clinical ophthalmic specialists and allied health-care professionals in the detection and management of common eye conditions can thus help to reduce the burden of eye disease and improve prognostic outcomes. Digital imaging has become a useful tool in facilitating eye-care delivery in both the community and hospital setting. In the last decade, the advent of electronic image exchange via a centralized referral unit in Scotland has revolutionized screening for ophthalmic disease, referrals, and shared care between community and HES clinicians. A government-led initiative known as the Scottish Eyecare Integration Project introduced electronic transfer of digital images within referrals from community optometrists to HES, which greatly reduced outpatient waiting times and improved patient satisfaction. The catalogue of live clinical information and digital images that resulted from the project led to the creation of a virtual learning platform through the University of Edinburgh. Participating professionals involved in eye care have interactive discussions about common eye conditions by sharing digital images of cases and investigations on a global online platform. This has received worldwide attention and inspired the creation of other university courses, e-learning platforms in eye-health education, and shared-care schemes in the screening of eye disease. We show that digital ophthalmology plays a vital role in the integration of community and HES partnership in delivery of patient care and in facilitating eye-health education to a global audience.
\end{abstract}

Keywords: eye health, patient care, digital imaging, teleophthalmology, shared care

\section{Introduction}

It is estimated that 256 million people are living with significant visual impairment and blindness, of which $65 \%$ and $82 \%$, respectively are above the age of 50 years. ${ }^{1}$ Globally, the incidence of people living with blindness has increased by $17.6 \%$ since 1990 , largely attributable to an increasing global and aging population. ${ }^{2}$ The Vision 2020 project, in collaboration with the International Agency for the Prevention of Blindness and the World Health Organization, aims to eliminate all avoidable blindness by $2020 .^{3}$ Although an ambitious target, there has already been significant improvement in the surgical management of cataracts, early detection and management of conditions resulting in childhood blindness, such as onchocerciasis, and uncorrected refractive errors. ${ }^{4}$ Despite this, the impact of public health interventions in eye care has been limited by overstretched health-care systems and a global shortage of ophthalmologists per million population. ${ }^{5}$ Consequently, there is a larger responsibility to educate and train nonophthalmic clinicians, optometrists, nurses, and allied health-care professionals in the detection and management of blinding eye disease. 
In this respect, digital ophthalmology has a useful and significant role, both with regard to direct ophthalmic care and as an educational tool. The image-based nature of this ophthalmology specialty and advances in image resolution and anatomical coverage make it hugely amenable to remote diagnosis, with positive patient and user outcomes. Integration of digital images obtained by using such software as fundus photography and optical coherence tomography (OCT) within referrals has revolutionized the diagnosis and management of patients with diabetic retinopathy and agerelated macular degeneration. Furthermore, photography of eyelid lesions within the primary-care setting has also proved useful in differentiating between benign and sinister pathology in referrals to hospital eye services (HES). Electronic communication with images also facilitates education of a far-reaching and multiprofessional audience. We describe the role of digital ophthalmology within the Scottish eye-care delivery service with reference to national ophthalmic service contracts, electronic communication, education, and direct patient benefits. We also describe the consequent global sharing of ophthalmic practice and training.

\section{Digital ophthalmology in eye-care delivery Scottish General Ophthalmic Service contract}

It is widely recognized that delivery of good-quality community eye care is instrumental in managing the growing demand of HES. Early identification and management of eye disease within the community can potentially reduce the burden of disease and improve prognostic outcomes. As the majority of referrals to HES are from primary care, investment in the primary eye examination is essential for early detection of sight-threatening pathology. This is in line with Royal College of Ophthalmologists guidance, which recognizes the importance of developing robust and refined referral pathways into HES to meet the increasing demand. ${ }^{6}$ As many conditions can be managed safely in the community, good education, training, and seamless communication among community practitioners and specialist clinicians is key to this process.

Under the General Ophthalmic Service scheme, community optometrists in Scotland are able to perform a tailored primary eye examination for each patient and further supplementary tests if required. First introduced in 2006, the scheme differs from the traditional sight test, as it allows optometrists to perform repeatable tests on patients prior to referral for specialist input. Importantly, this tailored eye test comes at no cost to the patient, making it widely accessible and an important pathway for screening. This Scottish government initiative is unique within the UK National Health Service (NHS), and has yielded higher-quality referrals to HES and a decrease in false-positive referral rates, particularly in the diagnosis of primary open-angle glaucoma. ${ }^{7,8}$ Furthermore, the role of the community optometrist has progressed from offering sight tests and corrective spectacles to being a primary-care provider in the management of common eye conditions. ${ }^{9}$

\section{Scottish Eyecare Integration Project 2012}

In line with Vision 2020, the Scottish government recognized the importance of electronic referral pathways to fully integrate eye-care services within Scotland. ${ }^{10}$ As both Internet and computer access is available to all community optometrists, there was growing incentive to promote electronic exchange of high-quality data to refine the referral process between primary care and HES. An electronic referral system in one Scottish health board (NHS Fife) had been proven to show many benefits, including reducing the referral time to treatment, improving one-stop allocation of patients to specialist clinics, and identifying those suitable for community care. Patient satisfaction was 97\% for this scheme, with particular reference to the immediate process of referral and appointment, less travel with remote diagnosis and integration of eye care, and keeping the community-care loop actively involved and informed. ${ }^{10-12}$ Furthermore, introduction of the electronic referral pathway reduced unnecessary referrals by $37 \%$ compared to those referred via the traditional paper method. ${ }^{12}$

Based on the success of this scheme the Scottish government health department pledged $£ 6.6$ million in 2012 to roll out electronic digital communications between optometrists and HES throughout Scotland. ${ }^{10}$ In 2012, there were over 50 different paper-based referral forms from the community to hospital in existence. These were amalgamated into five electronic referral forms that reflected the key information required for the main ophthalmic disease categories (cataract, macula, glaucoma, pediatrics, and general). Optometrists were connected to a virtual private network, known as the Scottish Clinical information Gateway, which could send patient referrals to HES. ${ }^{13}$ This network was already in place as a method of communication between general practice and HES. In addition to clinical information transmitted, support information, such as ophthalmic images, computerized visual field testing, and OCT images, could also be attached to the referral. Figures S1 and S2 are examples of one of the old 
paper referral forms alongside the new electronic referral form for suspected macular pathology. Figure S3 shows the rise in electronic referral rates across the 14 Scottish health boards from the initiation of the Eyecare Integration Project (EIP).

The average waiting times across all ophthalmic outpatient departments in Scotland have reduced from 6-9 months to $6-12$ weeks in the course of the last 6 years. ${ }^{14}$ A key support structure to this improvement was electronic referral. Cataract referrals are now seen and treated within 12 weeks of referral. The vast majority of macula referrals have image attachment to prioritize the level of urgency (Figure S4). All glaucoma referrals are required to complete the dedicated glaucoma referral form, which includes repeat applanation tonometry, computerized visual fields, corneal pachymetry, and disk images. Ophthalmic pathology that is longstanding and suitable for community follow-up is retained in the community with advice from HES. ${ }^{10,11}$ A national requirement through the EIP is direct feedback to the primary referrer on how the referral was processed and any additional clinical information required. This serves the process of continued refinement of the referral interface.

\section{Digital ophthalmology in global education \\ University of Edinburgh virtual learning- platform ophthalmology courses}

As a consequence of electronic referral with ophthalmic images, a vast library of clinical cases and support information was propagated within the ophthalmic subspecialties. This material was anonymized and catalogued, with the potential to create a variety of teaching and training tools. In 2014, the University of Edinburgh, in partnership with the Royal College of Surgeons and NHS Education for Scotland (NES), developed a virtual learning platform for ophthalmology. Discussion within these three major institutions agreed that investment in the platform would stand to elevate the standard of ophthalmic care in Scotland by promoting a higher level of professional and educational interaction among all providers of ophthalmic care. ${ }^{15,16}$

A master's degree (MSc) in Primary Care Ophthalmology was created in 2014. This degree was aimed primarily at qualified optometrists, ophthalmic allied health professionals, ophthalmic trainees, and junior doctors looking to enhance their knowledge of visual sciences and clinical ophthalmology. All students had access to a virtual ophthalmic library that stored a wide range of ophthalmic journals and textbooks.
Sensitive to the fact that all these professionals were fulfilling a daytime job, the degree was designed to be undertaken over 1-6 years. Additionally, the course could be undertaken at three levels, and on completion participants were accredited with a postgraduate certificate, diploma, or MSc degree. ${ }^{15}$ Course design was based mainly on the ophthalmic disease subspecialties that present to primary care. A key success was that all cases were live patient material presented by consultant ophthalmologists and optometrists (Figure S5). Senior ophthalmic trainees on the southeast Scotland ophthalmic training rotation also presented cases as part of their academic and educational training. Therefore, an entire patient journey from presentation to treatment was virtually visible to students. Consultants also delivered online lectures and posed clinical tasks within their subspecialties. Most popular have been the discussion boards that allow question-and-answer sessions in a virtual environment over several days. This high degree of interaction among consultant ophthalmologists, optometrists, junior doctors, and optometry tutors has proved invaluable in raising standards of care. The final year of the course involves a research project. Many of the topics chosen were highly relevant to the delivery of ophthalmic care in Scotland, and have been presented and published in the current literature with a view to sharing good practice. ${ }^{17}$

In the last 4 years, Scotland has evolved regional sharedcare schemes whereby in close communication between primary and secondary care, patients with mild or stable disease are monitored in the community. These conditions include postoperative cataract care, low-risk glaucoma, ocular hypertension, low grade uveitis, keratitis, minor emergency care (abrasions, corneal foreign bodies), and non-sightthreatening retinal lesions. ${ }^{18}$ This alleviates pressure within the HES and frees up clinical resources in secondary care for interventional sight-saving treatment for acute diseases, such as wet macular degeneration and vein occlusions. ${ }^{18}$ Many of the lead optometrists in these schemes have completed all or part of the University of Edinburgh online ophthalmology courses, giving them accreditation to practice at a higher standard. Other schemes in Scotland have allowed for direct referral from community to specialist clinics based on the improved referral information. ${ }^{18}$ The improved collaboration among ophthalmic care providers brought them together in a group, which published the Scottish Intercollegiate Guidelines Network (SIGN) glaucoma guidelines for Scotland. ${ }^{19}$ This further endorsed and gave guidance on risk assessment and management of glaucoma-suspected patients in the community and safe discharge of patients from hospital to the community. This document specifically took into 
consideration the arrangements in Scotland with regard to the General Ophthalmic Service, electronic connection, and higher accreditation.

Unsurprisingly the popularity of the courses and potential global reach resulted in a second course - Master of Surgery (ChM) in Clinical Ophthalmology - being designed in $2015 .^{20}$ This was aimed primarily at ophthalmologists and ophthalmic practitioners across the world in secondary care. The tutors were from both primary and secondary care, thus retaining the concept of $360^{\circ}$ patient care and management. There was more emphasis on interventional ophthalmology and emergency care. From sharing clinical experience within Scotland, a global community of students was created with a platform that discusses a wide expanse of global ophthalmic conditions. The final year of the ChM involves a research project, and the subject matter among global students has largely been in reference to the major eye-disease categories of cataract, glaucoma, and macula. Students have presented their work at international fora. ${ }^{21}$ There has also been global sharing and adaptation of national guidelines, such as SIGN. ${ }^{19}$

This global reach attracted attention from Vision 2020, the Royal National Institute for the Blind, and the International Glaucoma Association, all of which are actively involved in participating in and promoting the course. Charitable organizations and individual donors have contributed generously, with several scholarships created from benefactors supporting global ophthalmic care. Students from low-income countries are supported annually with laptops and course fees. It is hoped that with this support, the number of qualified ophthalmic officers is increased and both clinical support and international links are maintained via the university. The courses were awarded Queen's Anniversary Prizes for higher and further education. ${ }^{22}$
To date, delegates from over 40 different countries have participated in the MSc and ChM degrees.

\section{Discussion}

Digital imaging, which refers to the method of capturing, storing, and sharing images by means of camera or computer, has become increasingly important in modern day-to-day life and clinical education. The ease of image capture has also embellished our visual interpretation of medical conditions, particularly within ophthalmology. Advances in imaging technology mean that images of the eye are no longer restricted to its external surface: such structures as microscopic as lesions on the retina, choroid, and optic nerves are now also being captured digitally. This has strengthened our ability not only to detect and diagnose important ocular conditions but also to improve teaching about important eye diseases. ${ }^{23}$ Novel methods of digital imaging, particularly using smartphone technology, such as the Portable Eye Examination Kit (PEEK) Retina application, allow live-image capture of ocular structures by means of direct photography and/or video capture, which has proved beneficial for ophthalmic specialists working in rural settings, both in clinical practice and in education. ${ }^{24}$

There are several teleophthalmology programs in the UK, of which the most widely adopted is the national diabetic retinopathy-screening program (see Table 1). The success of this scheme is reflected by the fact that for the first time in 50 years, the leading cause of blindness in adults of working age is now inherited retinal disease, rather than diabetic retinopathy. ${ }^{25}$ Glaucoma referral-refinement schemes, such as the Community and Hospital Allied Network Glaucoma Evaluation Scheme showed that virtual assessment using applanation tonometry, Humphrey visual fields, and fundus photography provided useful risk stratification of

Table I Examples of digital ophthalmology pathways within ophthalmic care and education in Scotland

\begin{tabular}{|l|l|}
\hline \multicolumn{2}{|l|}{ Digital ophthalmology in clinical care } \\
\hline Scottish Eyecare Integration Project & $\begin{array}{l}\text { Integration of primary and hospital eye services using electronic referral pathways } \\
\text { within Scotland via the virtual private network known as the Scottish Clinical } \\
\text { Information Gateway }\end{array}$ \\
\hline Diabetic retinopathy screening (DRS) & $\begin{array}{l}\text { Nationwide virtual assessment and grading of diabetic retinopathy in all known } \\
\text { diabetic patients by means of fundus photography }\end{array}$ \\
\hline $\begin{array}{l}\text { Community and Hospital Allied Network Glaucoma Evaluation } \\
\text { Scheme (CHANGES) }\end{array}$ & $\begin{array}{l}\text { Virtual assessment of glaucoma suspects using digitized Humphrey visual fields, } \\
\text { fundus photography, and applanation tonometry }\end{array}$ \\
\hline Digital ophthalmology in global education & $\begin{array}{l}\text { Distance-learning degree available to allied health-care professions involved in eye } \\
\text { care and junior doctors in training }\end{array}$ \\
\hline Master of Science (MSc) in Primary Care Ophthalmology & $\begin{array}{l}\text { Distance-learning degree available to ophthalmologists and ophthalmic } \\
\text { practitioners }\end{array}$ \\
\hline Master of Surgery (ChM) in Clinical Ophthalmology &
\end{tabular}


glaucoma suspects. ${ }^{26} \mathrm{~A}$ virtual macular disease referralrefinement scheme using digital transfer of fundus photographs and OCT images showed that review was within 48 hours and a third of the referrals did not need to be seen in hospital. ${ }^{27}$ There are also several international teleophthalmology programs, one of the largest being a virtual eye camp set up in rural India that has screened nearly 20,000 patients. Patients requiring surgery were selected accurately and sent to the nearest treatment center. ${ }^{28}$

The Scottish EIP scheme is unique in that it is a truly national system offering an equitable standard of eye care to all patients. Its success, however, is largely dependent on ongoing comprehensive ophthalmic examination in the community, and our experience shows that this is a useful investment that benefits both patient care and appropriate use of resources. This is indeed recognized by the Scottish government, which has pledged to incorporate electronic system support into government mainstream budgets through eHealth departments. With an estimated cost of $£ 1$ million for the initial IT connections and technical support, the EIP scheme is now financed within the public health services and uses electronic communication in a consistent way to refine screening and treatment pathways for all ophthalmic disease. A somewhat similar scheme exists in southwestern Australia, where teleophthalmology is used on a national scale to screen for ophthalmic disease in an area that has 19 times less coverage than urban Australia. ${ }^{29}$

\section{VLE platforms in education}

The MSc and ChM degrees are delivered entirely online using a virtual learning environment (VLE) format, making it attractive and accessible on a global platform. VLE is widely recognized as an important tool in the delivery of higher education online. It is defined as a collection of software tools that enhance online academic administration, teaching, and research.$^{30}$ Its increasing use in education reflects the rapid adoption of online resources in the 21 st century. Delivery of education by means of VLE platforms relies on five main areas of functionality: distribution of information, dissemination of electronic resources, face-to-face communication interfaces for users, formative assessments, and management tools for online scenarios..$^{30}$ It is thus a useful and effective medium for sharing of digital information and resources among users with online access within both remote and urban areas. Via VLE, matriculated students are taught using a variety of online tools, such as personal live lectures, weekly image case-based discussions, and image-animated series. Importantly, the use of digital images in the discussion of case scenarios is encouraged, igniting an interactive global discussion about the investigation and management of important eye diseases. A particularly useful aspect is the ability to have multiple users simultaneously across the profession, thus promoting a high level of collaborative learning. As a result, VLEs have grown in popularity within academia and facilitated distance learning higher-education programs globally.

There are a plethora of ophthalmic e-learning resources. The Royal College of Ophthalmologists has designed e-learning modules for all members through Eye-Site, as has the International Council of Ophthalmology. ${ }^{31}$ Additionally, there are distance-learning courses offered by Ulster, Aston, and Sydney universities. The particular strength of the University of Edinburgh Ophthalmology programs is that they have included other major educational providers (NES, Royal College of Surgeons) and all grades of providers of "on the ground" $360^{\circ}$ eye care. Additionally, the educational material provided is in abundance and current from a national electronic referral scheme. Therefore, it offers a very comprehensive and clinical education across the profession.

\section{Conclusion}

It is widely accepted that teleophthalmology and VLE platforms are critical to the delivery of eye care and education and in achieving the goals of Vision 2020.32 This paper describes how digital communication within a national electronic referral scheme in NHS Scotland has improved ophthalmic screening, referrals, and shared care between primary and secondary services. Alongside ophthalmic care, it has also played a contributory role in the development of virtual learning platforms in ophthalmic education, thus expanding the benefits of digital communication among professionals involved in eye care on a global scale.

\section{Disclosure}

The authors report no conflicts of interest in this work.

\section{References}

1. Pascolini D, Mariotti SP. Global estimates of visual impairment: 2010. Br J Ophthalmol. 2012;96(5):614-618.

2. Bourne RRA, Flaxman SR, Braithwaite T, et al. Magnitude, temporal trends, and projections of the global prevalence of blindness and distance and near vision impairment: a systematic review and meta-analysis. The Lancet. 2017;5(9):888-897.

3. Pizarello L, Abiose A, Ffytche T, et al. VISION 2020: The right to sight: a global initiative to eliminate global blindness. Arch Ophthalmol. 2004;122(4):615-620.

4. Sommer A, Taylor HR, Ravilla TD, et al. Challenges of ophthalmic care in the developing world. JAMA Ophthalmol. 2014;132(5):640-644.

5. Blanchet K, Gilbert C, de Savigny D. Rethinking eye health systems to achieve universal coverage: the role of research. Br J Ophthalmol. 2014; $0: 1-4$. 
6. The Royal College of Ophthalmologists. The Way Forward, An Executive Summary (2017). Available from: https://www.rcophth.ac.uk/ wp-content/uploads/2015/10/RCOphth-The-Way-Forward-ExecutiveSummary-300117.pdf. Accessed July 29, 2018.

7. Ang GS, Ng WS, Azuara-Blanco A. The influence of the new general Ophthalmic services (GOS) contract in optometrist referrals for glaucoma in Scotland. Eye. 2009;23(2):351-355.

8. El-Assal K, Foulds J, Dobson S, Sanders R. A comparative study of glaucoma referrals in Southeast Scotland: effect of the new general ophthalmic service contract, Eyecare integration pilot programme and NICE guidelines. BMC Ophthalmology. 2015;15(1):1-8.

9. Dickey H, Ikenwilo D, Norwood P, Watson V, Zangelidis A. Utilisation of eye-care services: the effect of Scotland's free eye examination policy. Health Policy. 2012;108(2-3):286-293.

10. The Scottish Government. Eyecare integration Project (2014). Available from: https://www.gov.scot/Topics/Health/Services/Eyecare/ Integration. Accessed July 29, 2018.

11. Borooah S, Grant B, Blaikie A, et al. Using electronic referral with digital imaging between primary and secondary Ophthalmic services: a long term prospective analysis of regional service redesign. Eye. 2013; 27(3):392-397.

12. Cameron JR, Ahmed S, Curry P, Forrest G, Sanders R. Impact of direct electronic optometric referral with ocular imaging to a hospital eye service. Eye. 2009;23(5):1134-1140.

13. SCI Gateway Product Description. Scottish care information (2018). Available from: https://www.sci.scot.nhs.uk/products/gateway/ gate_desc.htm. Accessed August 12, 2018.

14. Information Services Department. National statistics for Scotland (2018). Available from: www.isdscotland.org. Accessed August 12, 2018.

15. MSc in Primary Care Ophthalmology \& ChM In Clinical Ophthalmology. University of Edinburgh (2017). Available from: http://www.ed.ac. uk/ophthalmology/masters. Accessed August 13, 2018.

16. Tendo C, Johnson M, Hall N, Sanders R. A 21st century eLearning ophthalmic experience. BUJO. 2015;3(1):1-3.

17. Pronin S, Brown L, Megaw R, Tatham AJ. Measurement of intraocular pressure by patients with glaucoma. JAMA Ophthalmology. 2017; 135(10):1030-1036.

18. Community Eyecare Services Review. Scottish government. (2017). Available from: https://www.gov.scot/Resource/0051/00516810.pdf. Accessed August 12, 2018.

19. Glaucoma referral and safe discharge: a national clinical guideline. Scottish Intercollegiate guidelines network (2015). Available from: https://www.sign.ac.uk/assets/sign144.pdf. Accessed August 13, 2018.
20. ChM In Clinical Ophthalmology. The Royal College of Surgeons \& University of Edinburgh (2018). Available from: http://www.ophthalchm. rcsed.ac.uk/. Accessed August 13, 2018.

21. Shevade B, Anand, N. 2018. Systematic review of optical coherence tomography - a monitoring tool in idiopathic intracranial hypertension. Poster presented at 102nd Oxford Ophthalmological Congress, 2-4 July 2018, Oxford.

22. Winners PP. The Royal anniversary trust. (2018). Available from: http:// www.royalanniversarytrust.org.uk/the-prizes/previous-prize-winners. Accessed August 13, 2018.

23. Timlin H, Sanders R. Electronic Communication and digital images: referral pathways and clinical uses in ophthalmology. In: Davey P. editor. Ophthalmology: Current Clinical and Research Updates. London, UK: Intech Journal; 2014;6:131-151.

24. Mohammadpour M, Heidari Z, Mirghorbani M, Hashemi H. Smartphones, tele-ophthalmology, and Vision 2020. Int J Ophthalmol. 2017;10(12):1909-1918.

25. Liew G, Michaelides M, Bunce C. A comparison of the causes of blindness certifications in England and Wales in working age adults (16-64 years), 1999-2000 with 2009-2010. BMJ Open. 2014;4(2): e004015-e004016.

26. Ratnarajan G, Kean J, French K, Parker M, Bourne R. The false negative rate and the role for virtual review in a nationally evaluated glaucoma referral refinement scheme. Ophthalmic Physiol Opt. 2015;35(5): $577-581$.

27. Kelly SP, Wallwork I, Haider D, Qureshi K. Teleophthalmology with optical coherence tomography imaging in community optometry. Evaluation of a quality improvement for macular patients. Clin Ophthalmol. 2011;5:1673-1678.

28. John S, Premila M, Javed M, Vikas G, Wagholikar A. A pilot study to improve access to eye care services for patients in rural India by implementing community ophthalmology through innovative telehealth technology. Stud Health Technol Inform. 2015;214:139-145.

29. Razavi H, Copeland SP, Turner AW. Increasing the impact of teleophthalmology in Australia: analysis of structural and economic drivers in a state service. Aust J Rural Health. 2017;25(1):45-52.

30. Trafford P, Yukari S. An Introduction to Virtual Learning Environments [dissertation]. Gakushuin Econ Pap. 2011;48(10):143-151.

31. Royal College of Ophthalmologists. Ophthalmology-e-learning for healthcare (2018). Available from: https://www.e-lfh.org.uk/ programmes/ophthalmology/. Accessed August 13, 2018.

32. Kumar S, Yogesan K. Internet-based eye care: Vision 2020. The Lancet. 2005;366(9493):1244-1245. 


\section{Supplementary materials}

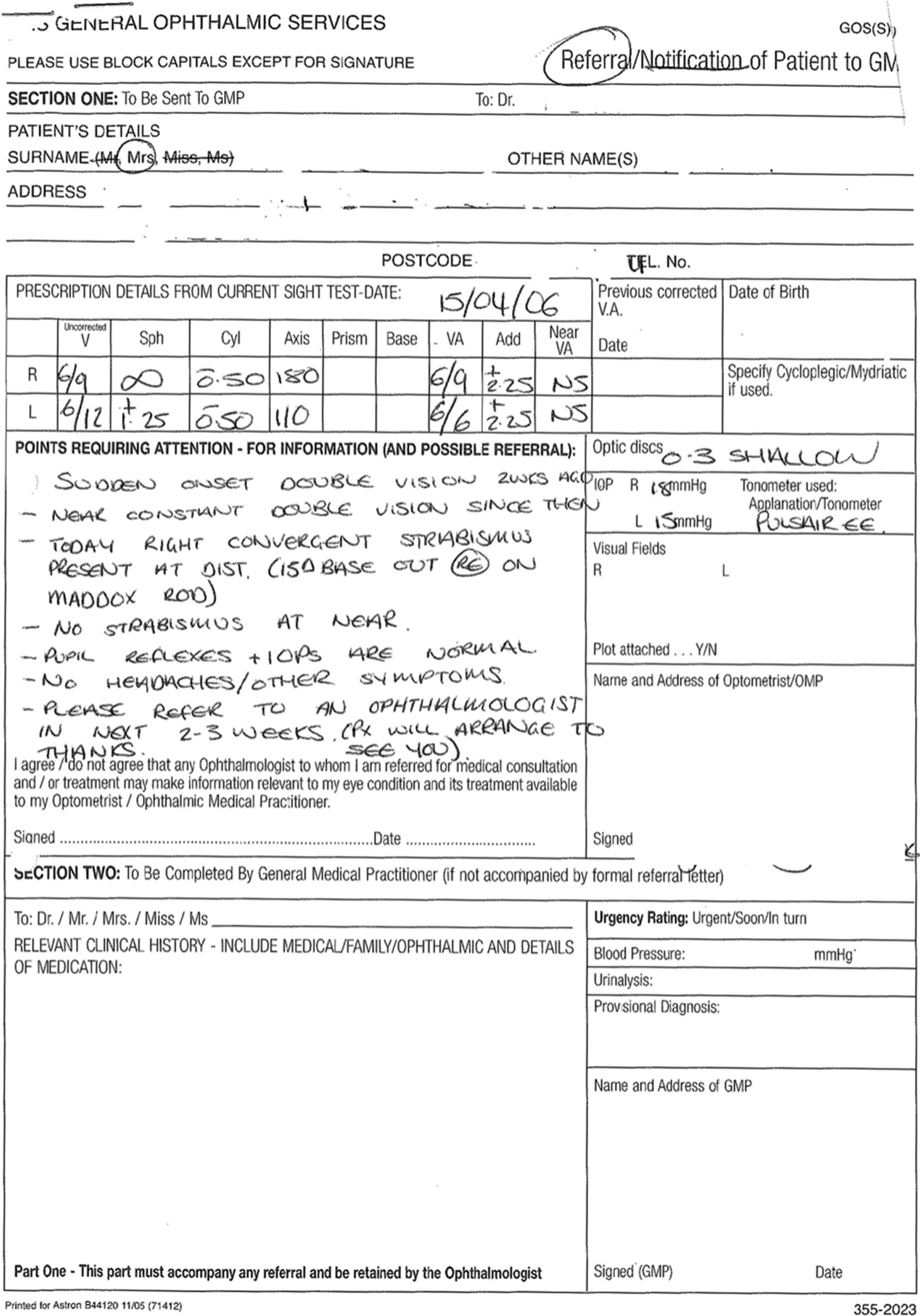

Figure SI Example of the previous nonelectronic referral form for acute ophthalmic pathology. 


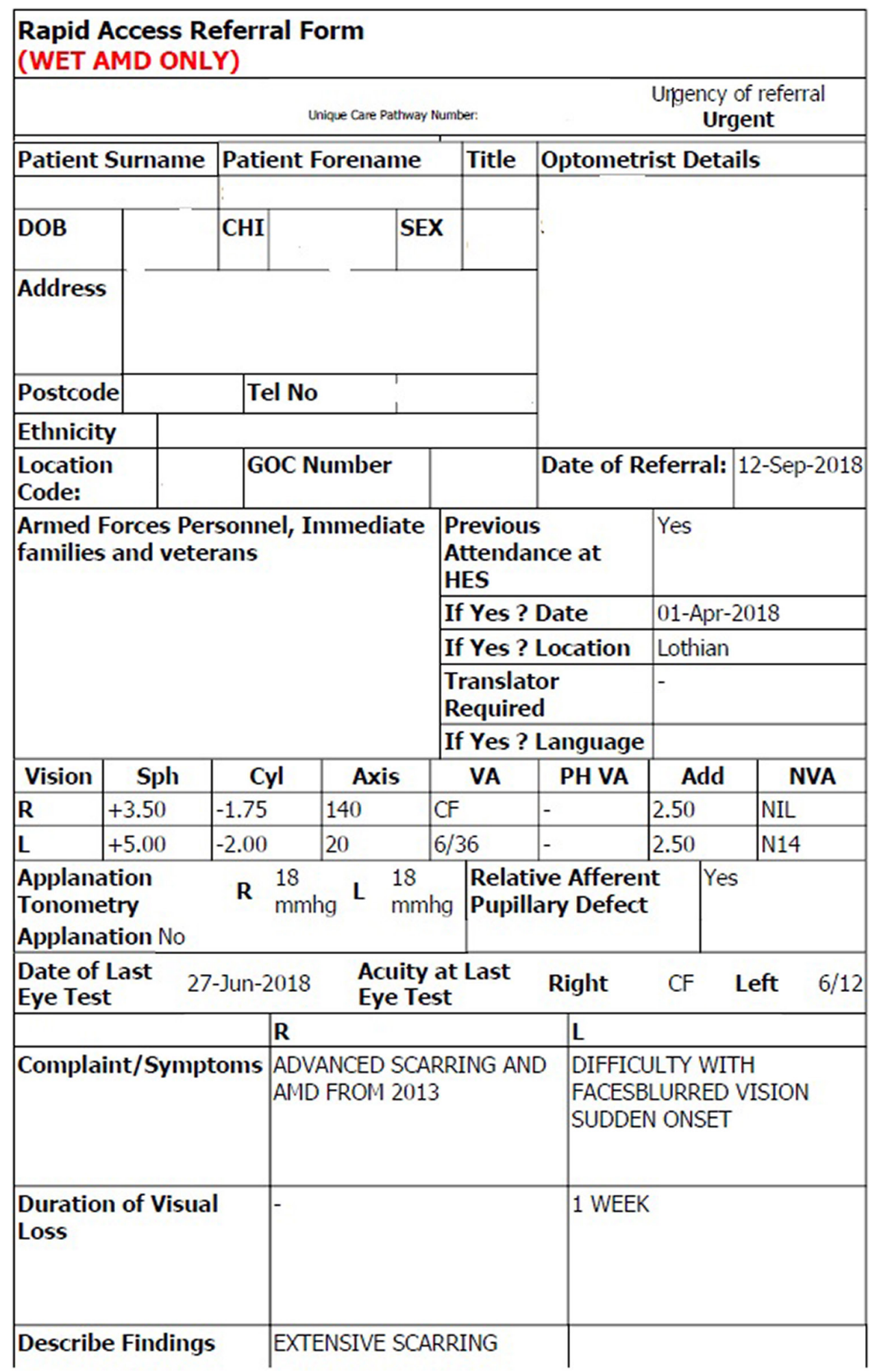

Figure S2 Example of an electronic referral form for suspected macular pathology. 


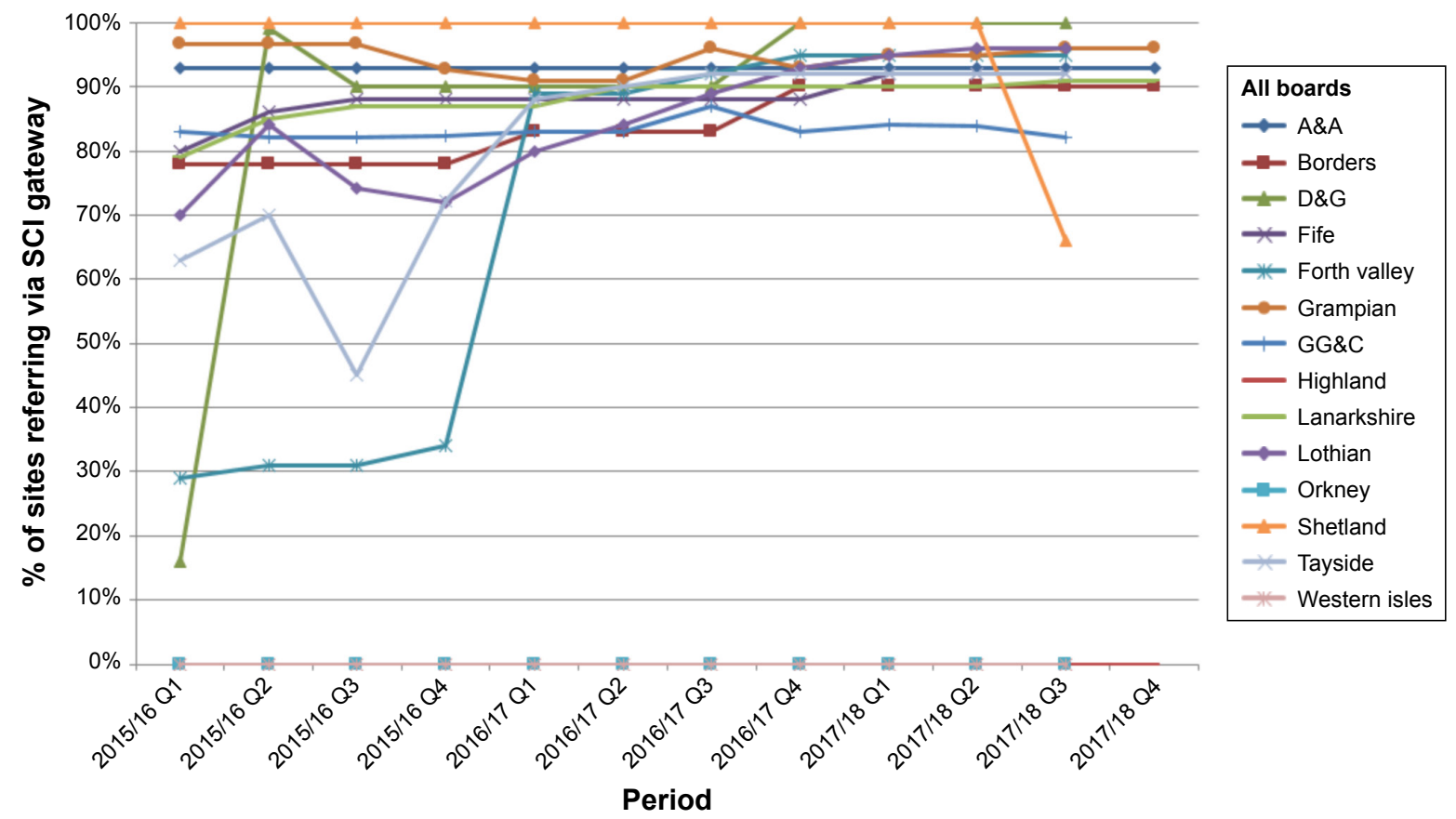

Figure S3 Rollout of electronic referral across 14 Scottish health boards between 2015 and 2017 . Abbreviation: $\mathrm{SCl}$, Scottish Clinical Information.

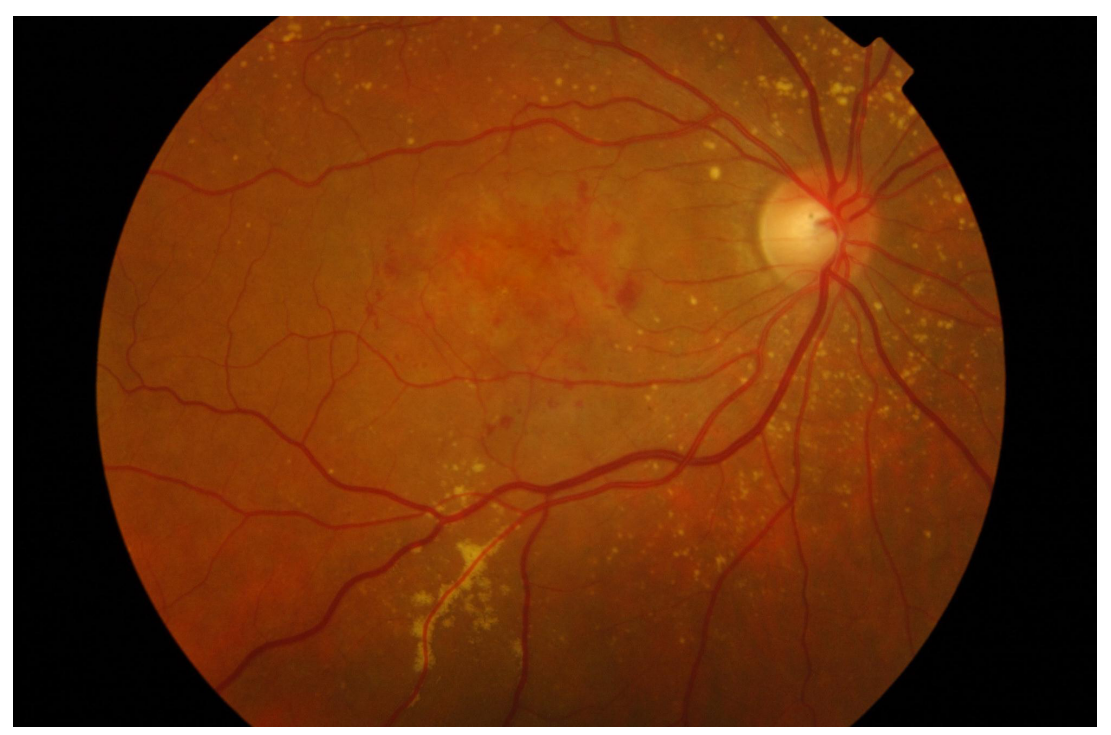

Figure S4 Example of a fundus photograph of a right eye electronically attached to an urgent referral to hospital eye services for suspected wet age-related macular degeneration. 

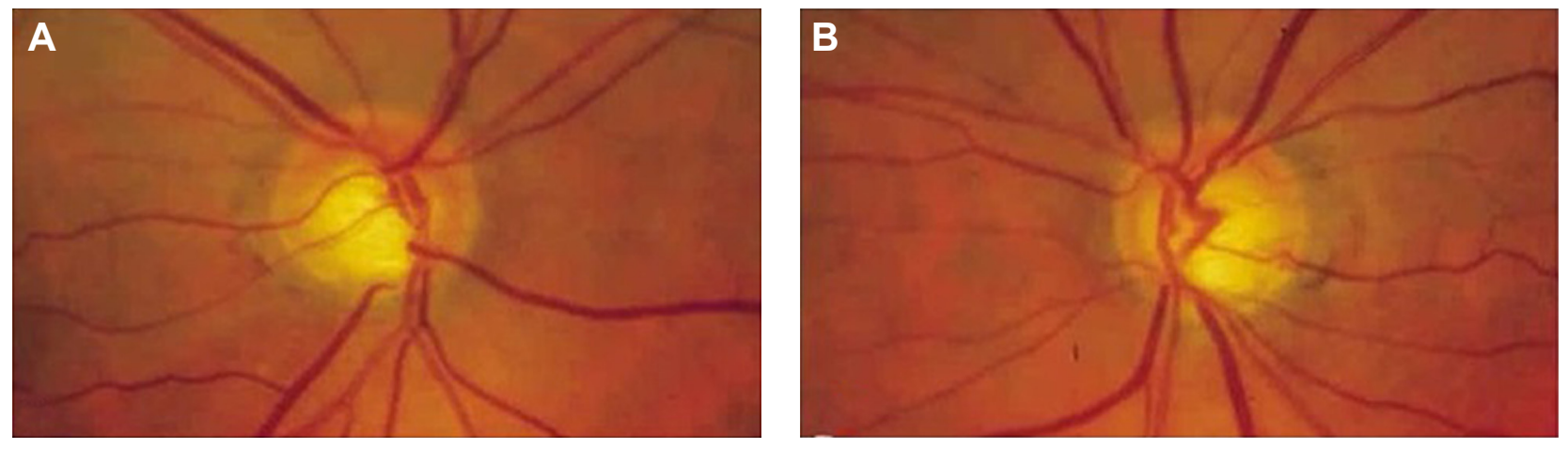

Figure S5 Images of case discussed and support material.

Note: Fundus photograph of optic nerve-head cupping (A, B).

\section{Publish your work in this journal}

Clinical Ophthalmology is an international, peer-reviewed journal covering all subspecialties within ophthalmology. Key topics include: Optometry; Visual science; Pharmacology and drug therapy in eye diseases; Basic Sciences; Primary and Secondary eye care; Patient Safety and Quality of Care Improvements. This journal is indexed on Submit your manuscript here: http://www.dovepress.com/clinical-ophthalmology-journal
PubMed Central and CAS, and is the official journal of The Society of Clinical Ophthalmology (SCO). The manuscript management system is completely online and includes a very quick and fair peer-review system, which is all easy to use. Visit http://www.dovepress.com/ testimonials.php to read real quotes from published authors. 